\title{
PERSPECTIVE
}

\section{An ATS/ERS report: 100 key questions and needs in occupational asthma}

\author{
S.M. Tarlo* and J-L. Malo\#, and other Workshop members
}

ABSTRACT: The second Jack Pepys Workshop on Occupational Asthma was held in Toronto, Canada, in May 2004. The present report summarises key questions and research needs as identified by the international participants.

The audiotapes from the workshop discussions were summarised by the organising chairs of the Symposium and the resulting document was circulated for input from all invited workshop participants. In total, 100 key questions and research needs were identified.

Identified needs included: provision of different definitions depending on the use of data; explanations for differences in frequency studies; and better characterisation of genetic and environmental determinants of occupational asthma. The role of irritants and the pathogenesis of various forms of work-related asthma need further research, and there are also questions and research needs for diagnosis, prevention and understanding of persistence and airway remodelling.

In conclusion, although advances have been made in the understanding of occupational asthma and other work-related asthma, further key issues remain that need addressing.

\section{KEYWORDS: Asthma, occupational asthma, work-related asthma}

\section{BACKGROUND}

Work-related asthma continues to be one of the most common groups of occupational lung disorders. The first Jack Pepys Occupational Asthma Workshop was held in 2001 [1]. It is hoped that this event favoured awareness of work-related asthma. The present report is intended to highlight key issues, questions and needs that were raised during the second Jack Pepys Occupational Asthma Workshop, which was held in May 2004. From the very beginning, the authors recognised that the issues and questions addressed varied from general to specific, and the priority of each would vary according to the domain of intervention (clinical, public health, basic research, etc.), as would the ease in which they may be addressed. The current authors have not attempted to prioritise these in the present report. Similarly, issues that may be addressed by changes in policy rather than by research have not been separated. The present authors also acknowledge that this document principally addresses issues and concerns that are more specific to developed rather than developing countries. Finally, in order to keep to a concise format, extensive referencing and discussion have not been added, since many relevant references are available in recently published excellent reviews [2-8].

\section{ISSUES OF DEFINITIONS}

Occupations that have been reported to carry an increased risk of asthma differ between community studies and clinical surveys [9-13]. One. Could the difference between these two approaches be due to different definitions of asthma? As an example, do cleaners, reported in community studies to have a significantly increased risk of asthma [14], but seldom identified in clinical studies, really have occupational asthma (OA) or is this another disease? Two. There is likely to be less referral of some workers to OA clinical centres due to a lack of workers' compensation coverage or the lack of consideration of occupational causes by healthcare providers. Does this explain a lag between clinical reports and community-based studies?

Three. Community studies are likely to include workers with undiagnosed asthma and those with underlying asthma which is aggravated by work exposures, in addition to those with OA.
AFFILIATIONS

*University of Toronto, Toronto, ON and

\#University of Montreal, Montreal, QC, Canada.

\section{CORRESPONDENCE}

S.M. Tarlo

Division of Respiratory Medicine

Toronto Western Hospital

New East Wing 7-449

399 Bathurst Street

Toronto M5T 2S8

Ontario

Canada

Fax: 14166036763

E-mail: susan.tarlo@utoronto.ca

Received

May 302005

Accepted after revision:

October 032005

\section{SUPPORT STATEMENT}

The 2nd Jack Pepys Occupational Asthma Workshop was supported by American Thoracic Society, European Respiratory Society, Canadian Institutes for Health Research (CIHR), Ontario Workplace Safety and Insurance Board (WSIB), Institut de recherché Robert-Sauvé en santé et sécurité du travail (IRRST) du Quebéc and Commission de la santé et sécurité du travail (CSST) du Québec. 
Does this explain differences from what is seen clinically and can these groups be better characterised in follow-up studies? Even when studies include pulmonary function or a single methacholine/histamine challenge, this does not confirm OA, but merely asthma. Clinical studies are needed in combination with population-based studies to determine what proportions of those with a case definition of OA truly fulfil clinical criteria for OA.

Four. Asthma that limits working ability and aggravation of asthma may be more common than $\mathrm{OA}$ and both conditions need more research [15]. How should aggravation of asthma be diagnosed? Objective support for occupational aggravation of asthma might only be feasible (by peak flow monitoring and symptom/medication diaries) if the aggravating factors at work are relatively low-level and chronic rather than intermittent and acute. Therefore, additional objective diagnostic measures need to be developed.

Five. The relatively low socio-economic status of a significant proportion of workers at risk of work-related asthma may impair chances of early diagnosis. More research is needed to characterise these issues and identify education needs and methods for early diagnosis. Broader population studies may help by reduced selection of specific groups.

Six. How should work-related asthma be classified when symptoms are induced solely by conditions at work that commonly aggravate asthma, rather than conditions that induce airway hyperresponsiveness (AHR)? For example, asthma symptoms may only occur by working in a freezer with cold air exposure. Population studies show increased relative risks of symptomatic asthma, raising the question as to whether some reports of asthma symptoms may occur from a subset of workers who have underlying mild (and, under normal circumstances, asymptomatic) AHR rather than the induction of AHR by a work exposure. Seven. Could irritant exposures (for example, in cleaners) cause a prolonged duration or recurrence of asthma in workers with previous asthma who may otherwise be asymptomatic, rather than increasing the incidence of asthma?

Eight. How can case definitions of OA best suit the reason for the definition? While there is a need for inclusive and less specific definitions in medical surveillance and for public health purposes, in order to intervene for the larger group of workers with symptoms, the definitions required for individual clinical diagnosis need to be both sensitive and specific in order to detect affected workers, but to avoid any unnecessary job change and socio-economic loss from an incorrect diagnosis. Ideally, classifications would include the cause, pathology, cytology and physiological characteristics, but, clinically, if resources are not available for an objective diagnosis then failure to provide a provisional diagnosis may be detrimental to the patient. Since there is often a mixture of sensitisers and irritants in a given workplace, a definition requiring a specific causative agent may lead to confusion and under-diagnosis, especially in patients with asthma at work over a prolonged period when the inciting agent may no longer be present. Studies are needed to determine the best ways to balance these needs.
Nine. For epidemiological purposes, is there a better way to define work-related asthma [16]? By using the term "OA", the cause is being put into the definition. Should this change? Perhaps the question should not be "What does OA mean?", but we should first ask the purpose of the question and then use a term to describe the condition. From a public health perspective, the presence of work-related asthma-like symptoms is of significance even if these are not due to objectively confirmed asthma, but research is needed to better define the causes of such symptoms and to assess whether another term may be a better descriptor.

Ten. Some legal systems exclude patients with pre-existing asthma from the diagnosis of $\mathrm{OA}$, even if the patient has become specifically sensitised to a work agent. Studies are needed to identify the relative prevalence of such new sensitisation in those patients with underlying asthma, and the prevalence of such a policy among compensation systems so that compensation systems can be provided with information to better inform decision making.

Eleven. In a similar way to differences in definitions of diagnosis for clinical versus public health versus epidemiological studies, there may be differences in the definitions of exposure. In assessing relative risk from epidemiological studies the estimate of exposure needs to have little "noise", but in public health decisions, especially pertaining to work aggravation of asthma, there may be the need to have a broader characterisation, e.g. by confirming if there has ever been exposure to dusts, fumes or gases. In contrast, for OA related to a sensitiser, the exposure needs to be well defined and there is call for better characterisation of these needs.

\section{PREVALENCE AND INCIDENCE ISSUES}

Twelve. Birth cohort studies of groups who are now reaching employment age may be able to provide information on workrelated asthma incidence and risk factors.

Thirteen. Studies suggest there are geographical variations in asthma [17]. If so, are these due to variations in occupational exposures or due to differences in co-exposures and susceptibility? Fourteen. Why do hairdressers (with persulphate sensitisation as a major cause of OA) appear in the main causes of OA in some countries, such as France and Sweden, but not in other countries [11, 18]? Could this relate to information given to family physicians from specialists, raising relative awareness of risks in some occupations?

Fifteen. Epidemiological studies should consider sex as a stratifying factor, since the sex distribution is often not equal in different occupations, e.g. professional domestic cleaners are more often female, but cleaners in some other settings have a male predominance. Some unpaid occupations, e.g. homemaker or hobby farmer, may be relevant to consider as cofactors in comparison groups when studies consider those working in paid occupations.

Sixteen. It should be determined whether epidemiological studies refer to occupational airways disease rather than "asthma" [19], as often the diagnosis of asthma versus occupational chronic obstructive pulmonary disease is not clear from questionnaire studies and symptoms may not be associated with pulmonary function changes. 
Seventeen. Later clinical investigations in some studies have reported that only $\sim 40 \%$ of those with self-reported workrelated asthma symptoms actually have objectively confirmed asthma. Is this because some have subsequently lost their asthma, have eosinophilic bronchitis [20] or have another cause for symptoms? Detailed clinical assessments of subgroups in epidemiological studies may address these questions.

Eighteen. Perception of the presence of respiratory symptoms can be influenced by many factors and can change over time, which may affect epidemiological studies if there is no objective measure of asthma. There is a need to identify these factors in order to interpret apparent changes in prevalence studies.

Nineteen. The evolution of OA incidence is difficult to assess with non-validated surveillance systems. Is the incidence of $\mathrm{OA}$ declining as suggested by the clinical experience of OA centres in Italy, but unlike the surveillance findings in France [21]? Twenty. How much under-recognition/under-reporting of OA still occurs? Are apparent declines in rates only occurring due to certain agents such as latex and diisocyanates, and is this due to preventive interventions?

\section{WHO GETS OA? GENETICS, OTHER HOST FACTORS AND ENVIRONMENTAL DETERMINANTS}

Twenty-one. Several reports have suggested associations between genetic markers and OA. Given the limitations of worker populations including small sample sizes, different durations of exposure, and difficulties in fully characterising OA phenotypes, can candidate genes be identified for further studies?

Twenty-two. Gene expression may be altered with environmental exposures. Is OA a suitable model to study environmentalgenetic interactions? Consensus is needed to define a specific OA phenotype so that further studies may allow the understanding of occupational environmental influences and genetic influences.

Twenty-three. What are appropriate control groups for epidemiological genetic studies in OA? Appropriate controls may need to be those patients who have had a similar exposure at work for $\geqslant 2$ yrs and who have not developed OA despite the opportunity to do so. Studies of families with shared exposures are unlikely to be available in most occupational settings, unlike other environmental studies.

Twenty-four. Many issues are similar to those of genetic studies of other diseases. When genetic associations with OA are made, to date they have often not been replicated. Will future studies be able to identify genetic markers in different background populations, such as European versus North American populations? Twenty-five. Can they be used for more than hypothesis generation, which is the main current use? Twenty-six. Do studies initially need to assess associations with specific causes of $\mathrm{OA}$ without considering details of the environmental exposure, or is it better to begin with geneenvironment interaction studies?

Twenty-seven. There are many ethical concerns regarding potential applications of genetic findings. While they may be used as steps in understanding the pathogenesis, or as a means to customise surveillance programmes, there are concerns that workers might be profiled to determine whether they have multiple risk factors for OA and their work options could be restricted. Twenty-eight. How would ethical safeguards be put into place to prevent infringement of the workers' freedom of choice and protection of the workers' privacy?

Twenty-nine. Is the genetic influence on OA mainly relevant as a risk factor in those with lower rather than higher exposures to sensitisers, as suggested in those exposed to complex platinum salts?

Thirty. Why does smoking appear to increase the risk of sensitisation to some agents [22], but reduces the risk for sensitisation to others?

Thirty-one. Why do many apprentice animal care workers, or other workers at increased risk of allergic sensitisation, not selfselect to other occupations before entering training programmes [23]?

Thirty-two. Will exposure control continue to be the most effective primary preventive strategy, as illustrated by employees in the detergent industry [24] and in healthcare workers with natural rubber latex exposure [25], or will nonsensitising substitutes be developed?

\section{IRRITANTS AND ASTHMA VARIANTS}

Thirty-three. Biological markers to identify the effects of irritants on the expression of asthma are needed. For example, could Clara-cell proteins be useful, similar to their use as markers of ozone exposure? Thirty-four. What changes can be seen in induced sputum cytology?

Thirty-five. How does the asthma-like syndrome in pig farmers relate to work-related asthma [26]? It may be a form of irritantinduced asthma, although many have no change in spirometry and those with airflow limitation often have no significant response to bronchodilators and do not have airway eosinophilic inflammation. Variable airflow limitation or AHR is present in some, but not all, with asthma-like symptoms.

Thirty-six. Can vocal cord dysfunction be caused by a similar mechanism as irritant-induced asthma? Thirty-seven. Can increased cough sensitivity be induced by irritant exposures, perhaps via an effect on $C$ fibres as suggested in studies of capsaicin challenge in guinea pigs after halothane exposure? Thirty-eight. How can this be objectively assessed? Would noninvasive markers of inflammation such as exhaled nitric oxide (NO) be useful for assessing irritant airway effects? Thirty-nine. What is the role of a low airway $\mathrm{pH}$ in inducing cough? Forty. Can pharmacological blockers of $\mathrm{C}$ fibres be developed that are more effective than nedocromil? Forty-one. What is the meaning of increased sputum neutrophils after irritant exposures?

Forty-two. Among workers with asthma-like symptoms after irritant exposures, how many have true irritant-induced asthma versus bronchitis, vocal cord dysfunction, post-nasal drip or gastro-oesophageal reflux?

Forty-three. Are underlying host factors more important in the response to low-level irritant exposures than to massive accidental exposures?

Forty-four. How can a diagnosis of irritant-induced workrelated asthma be reached clinically if a patient is seen after a 
period of time away from the implicated exposure and pulmonary function parameters are normal at that time? Current diagnostic tests cannot confirm or refute the diagnosis.

Forty-five. If multiple low-level irritant exposures can cause repeated episodes of bronchospasm and mechanical stress on smooth muscle, with the release of cytokines, then what is their role in the onset of symptoms in workers with work-related asthma?

Forty-six. What is the distribution of airway injury due to irritant-induced asthma? Is it uniform within the bronchial tree? Is there associated bronchiolitis or alveolitis?

\section{PATHOGENESIS \\ General mechanisms}

Forty-seven. Studies in work-related asthma have learnt from nonwork-related asthma that asthma is extremely heterogeneous. Understanding of the underlying pathogenesis is very important for management and should be addressed in research studies.

Forty-eight. The onset of airway obstruction, AHR and inflammation may not necessarily be synchronous in OA. The timing of these events should be examined.

Forty-nine. There is often more than one airway stimulant contributing to airway inflammation in an individual, such as smoking, viral infection and air pollutants, as well as the occupational exposure, which could confound the interpretation of induced sputum cytology. Is the clinical history at the time of testing the best way to determine the influence of these confounders?

Fifty. Is it too restrictive to characterise OA as immunological and nonimmunological in origin, since nonsensitisers can also cause inflammation and might also contribute to sensitisation, as with diisocyanate exposures, perhaps even with nonmassive irritant exposures? Therefore, should the expressions allergic and nonallergic OA be preferred and how do neutrophils fit into the classifications?

Fifty-one. Data from animals suggest that a sensitising agent can be absorbed through the skin [27]. Key questions related to this warrant exploration in humans, such as the following. 1) Is the skin a site of absorption that can lead to respiratory sensitisation? 2) Is the response to an agent similar if the agent is absorbed through the skin or through the respiratory tract? Fifty-two. How useful are animal models in predicting the ability of a chemical to cause sensitisation and in understanding the pathogenesis of OA?

Fifty-three. The outcome of high and low molecular weight agents, when inhaled, is unknown, particulaly if they are transformed and coupled to act as haptens. Can inhaled agents (i.e. persulphates) change the $\mathrm{pH}$ of the airways and cause an asthmatic reaction? How long do occupational agents stay within the airways where they can exert a long-lasting immunological effect? Can tolerance occur with occupational sensitisers in a similar manner to nonoccupational allergens?

Fifty-four. The mechanism of asthma caused by low molecular weight agents is still unknown. How does the immune system recognise a low molecular weight agent and generate a specific response?
Fifty-five. In OA, a better knowledge and description of the events that occur in the upper airways should be obtained with the concept of "united airways" (i.e. a continuous upper and lower respiratory system with common mechanisms of response [28]), and an association should be made with events in the lower airways.

\section{The role of cells}

Fifty-six. Eosinophilic bronchitis can occur alone or progress to clinical asthma or airflow limitation [29]. How can the outcome of occupational eosinophilic bronchitis best be predicted? The role of neutrophils is discussed more and more in the physiopathology of asthma. Are there differences in OA? Their role in the aetiology of asthma in the workplace and in the persistence of asthma after removal from exposure has to be examined thoroughly. Fifty-seven. Neutrophils appear to be predominant in severe asthma [30]. Are they only markers of the severity of asthma? Are they determinants of poorer prognosis from OA if they are present at the time of diagnosis?

Fifty-eight. What are the roles of the various components of the inflammatory reactions that have been recently identified in OA? The various components include: dendritic cells (protease-activated receptors); $\gamma$ and $\delta$ T-cells; the epithelial layer (laminin); mast cells; and specific types of lymphocytes and monocytes.

\section{Questions specific to a single group of compounds}

Fifty-nine. What are the antigens or active sensitisers in diisocyanate-induced asthma? Do they result from metabolites and how can these best be developed for reproducible laboratory diagnostic tests? What is the main target protein? What is the role of glutathione? What is the role of a low $\mathrm{pH}$ affecting the stability of reactions with glutathione and carbonate buffering of the airway acting as a catalyst for breakdown of the products? Can urinary metabolites of some chemicals, such as isocyanates, be used to assess the level of exposure. Is there an association between the level of urinary metabolites and the likelihood of developing OA to isocyanates?

Sixty. What is/are the mechanism(s) of OA induced by persulphate in hairdressers? Not all seem to have specific immunoglobulin (Ig)-E antibodies and the skin-test responses are not typical for IgE antibody responses.

\section{QUALITY OF LIFE AND DISABILITY}

Sixty-one. Quality of life (QoL) in OA has only been examined by standardised questionnaire in one study in which it was shown that it is marginally less satisfactory than in a matched group of asthmatic subjects with the same severity of asthma [31]. However, QoL may vary depending on the populations examined. In addition, the medico-legal compensation that is offered probably plays a major role. The QoL in various populations affected by asthma in the workplace should be examined worldwide.

Sixty-two. The cost of OA should also be examined in different countries. What should be done next to reduce socio-economic losses due to asthma in the workplace [32]? Loss of income and severity of asthma may both be contributors to QoL in OA. It would be important to know the relative influence of each of these factors in influencing the QoL of subjects with OA. 
Sixty-three. Initiating a claim to a workers' compensation system may cause prejudice to the worker, making their ability to find new work more difficult. Even when a claim is accepted, it may lead to minor financial gains and overall income loss. The consequences of initiating a claim for workrelated asthma should be documented in different countries.

Sixty-four. What weight should be given to the inability of a worker to carry on with his usual work (as well as considering impairment and disability) in compensating subjects with OA?

Sixty-five. Psychological factors have not been examined in subjects entering "at-risk" workplaces, subjects who develop work-related asthma, or in subjects after they develop OA. Therefore, it is relevant to know whether psychological factors are involved in the aetiology of work-related asthma and how psychological factors complicate the treatment and outcome of OA.

Sixty-six. QoL instruments are high-performing tools in the follow-up of asthma and could be used to monitor the progression of asthma in the workplace. There is a need in research to incorporate these in future studies.

\section{ENVIRONMENTAL DETERMINANTS OF WORK-RELATED ASTHMA}

Sixty-seven. Both median levels of exposure and peak levels may be relevant in the onset of sensitisation to an occupational agent. In the case of sensitising occupational agents, what defines a peak and when is it biologically relevant? Peak exposures may be the rule more often than the exception. Should intervals of nonexposure between episodes also be included as potential determinants?

Sixty-eight. Flour is a common cause of OA. It may contain allergenic additives, as well as contaminants, such as insect parts. Wheat itself represents a complex allergenic mixture. What are the constituents of wheat and what is the allergenic potential of each? A recommendation of an upper threshold that appears significant in inducing sensitisation has been made in the case of flour dust $\left(2 \mu \mathrm{g} \cdot \mathrm{m}^{-3}\right)$ [33]. The thresholds and other exposure determinants for sensitisation of key occupational allergens need to be determined.

Sixty-nine. Workers exposed to isocyanates can demonstrate asthmatic reactions to oligomers and pre-polymers of isocyanates [34]. The respective contribution of oligomers and pre-polymers in inducing sensitisation is unknown and worth exploring. Should exposure standards for isocyanates be modified to take into account different chemical forms of isocyanates, not only monomers, and consider not only respiratory but also skin absorption?

Seventy. Pollutants play an enhancing role in the induction of asthmatic reactions due to common allergens. What is the influence of other contaminants (physical and chemical stimuli, tobacco smoke) in the process of sensitisation, development of symptoms and asthmatic reactions due to occupational allergens? What is the role of infection, irritant exposure (including air pollutants, such as indoor terpenes, ketones and possible reaction products from ozone) and exercise in the development of specific sensitisation and subsequent OA? Is there an interaction between these via the release of inflammatory mediators, heat shock proteins or effects on toll-like receptors? If relationships are found, can these be prevented?

Seventy-one. Do endotoxins cause or contribute to symptoms in nonsensitised subjects exposed to a variety of occupational agents, including low molecular weight agents? Do endotoxins exert a protective role on sensitisation to occupational allergens as has been suggested for the development of atopy in early childhood, or do they act as an adjuvant to increase risks of sensitisation and symptomatic responses [35]? Can the potential of irritants to act as adjuvants be assessed and quantified? Is there a "window of opportunity" for different effects of endotoxins in relation to OA?

Seventy-two. Starch has been identified as an important allergen carrier of latex. Starch is also a carrier of Lollium in pollen grains, which may be relevant for outbreaks of asthma in thunderstorms. There should be better understanding and focus on the role of allergen carriers for various occupational agents.

Seventy-three. It has been shown that the relationships between exposure and sensitisation may vary in atopic and nonatopic subjects. The relationships between exposure and sensitisation for specific occupational agents have to be determined.

\section{PERSISTENCE AND REMODELLING}

Seventy-four. Besides duration of exposure, duration of exposure with symptoms, and severity of asthma at diagnosis of $\mathrm{OA}$, what are the other determinants of the persistence of asthma after removal from exposure? Why don't all patients recover? The possibilities of further exploration include: 1) sensitisation to an agent present in the general environment (e.g. latex) or cross-reactivity; 2) sensitisation to common environmental agents (which seems the least likely); 3) occupational antigens still present in the airways; 4) autoimmune response; 5) neoantigens; and 6) genetic predisposition to airway remodelling (e.g. through ADAM-33, tumour growth factor- $\beta$ and glutathione genetic predisposition).

Seventy-five. What is the role of oxidative stress both in OA with a latency period and irritant-induced asthma? Which cells and cytokines are involved in the persistence of symptoms in irritant-induced asthma? Seventy-six. How can the design of studies in irritant-induced asthma be improved so that enough cases are studied prospectively?

Seventy-seven. Despite strong medical advice to discontinue exposure to a work sensitiser, some patients with OA continue to work in the same environment with the same or reduced exposure. What is the value of inhaled steroids in such patients?

Seventy-eight. Subjects with OA are exposed to common allergens after being removed from work. In the case of OA due to low molecular weight agents, is there cross-reactivity with other common environmental chemicals that resemble the causal agent?

Seventy-nine. In aiming to assess the efficacy of intervention in work-related asthma, a problem in the design of postintervention studies is that there is usually no control group. How can this study design problem be overcome? 


\section{DIAGNOSIS}

Eighty. Noninvasive tools designed for examining airway inflammation, induced sputum [36, 37] and exhaled NO [3840] have been proposed for diagnosis, but are too often only used for research. How should the use of these instruments be broadened when shown to be effective?

Eighty-one. What is the interpretation of induced sputum cytology in those with work-related asthma symptoms? Do allergens and sensitisers always induce eosinophilic inflammation and can they sometimes induce neutrophilic inflammation? This has been suggested by animal studies and by some studies of patients with OA. Why have neutrophils been predominant in laboratory isocyanate challenge responses, but eosinophils in workplace exposure studies [41]?

Eighty-two. Induced sputum neutrophilic inflammation (i.e. increases in counts and proportion of neutrophils) can occur with an infective process or with irritant exposure, such as cigarette smoke, as well as with many innocuous stimuli. If this occurs after diisocyanate exposure, does this mean the inflammation was from irritation to the airways rather than from a specific immunological sensitisation? Does an increase in neutrophils in induced sputum suggest a nonspecific response? How can these possible mechanisms be separated for studies of OA? Eighty-three. Studies are needed of sputum cell counts after exposures to noxious agents such as chlorine gas.

Eighty-four. Should sputum neutrophils be examined for evidence of activation or specific markers in subjects with $\mathrm{OA}$, since there is such a wide range of normal sputum neutrophil counts?

Eighty-five. Can neutrophilic airway inflammation from occupational exposure lead to AHR as it can with viral infections? What is the effect of chronic airway neutrophilic inflammation?

Eighty-six. Monocyte chemoattractant protein (MCP)-1 seems to be a specific and sensitive tool in the diagnosis of OA due to isocyanates [42]. What is the validity of MCP-1 assessment in OA due to other agents besides isocyanates?

Eighty-seven. The investigation of OA may be hampered due to the distances to large centres where investigation means are offered. How can simple diagnostic tools be applied, used and validated in regions where no specialised diagnostic facilities are available? Eighty-eight. The best ratio of the number of specialised centres offering expertise in OA to the working population has to be set in order to make specific inhalation challenges with occupational agents and other testing for work-related asthma, safe, readily available and of a high-quality standard.

Eighty-nine. Functional and inflammatory tests of the nose are not as standardised as those aimed at assessing the lower airways. How can the methodology of nasal challenges and understanding of relationships with OA be improved?

Ninety. How can better information be obtained on the barriers to diagnosis? Why is there under-diagnosis? Why are there delays in referral [43]? Are these more closely related to socioeconomic factors? These issues should be examined by multidisciplinary researchers, i.e. sociologists, psychologists and economists.
Ninety-one. Residents in internal medicine are not sufficiently exposed to the investigation of OA. How can the content of teaching programmes for residency training be improved?

\section{PREVENTION}

Ninety-two. How can the importance of work-related asthma be better communicated to the public and to workers?

Ninety-three. The current financial cost of OA is not great for industries. What would motivate industries to offer financial support to prevent the condition and offer satisfactory compensation programmes to affected workers?

Ninety-four. Reducing exposure and enhancing awareness of asthma in workers at risk are two key points in surveillance programmes. How should efforts at improving education of workers be conducted? Should these focus on initial symptoms if they are really predictive of sensitisation and OA?

Ninety-five. Should interventions focus on specific time intervals after starting exposure, as sensitisation is most common in the first 2-3 yrs (at least for high molecular weight agents)?

Ninety-six. How can public health responsible agencies promote surveillance? Should medical surveillance programmes be mandated in all workplaces using known respiratory sensitisers?

Ninety-seven. Is it realistic to try to set thresholds for all occupational agents, since there are a large number of agents causing OA? How can hazard assessment be improved?

Ninety-eight. Should industries label compounds as sensitisers? How can risk management be improved? Ninety-nine. How do behavioural aspects, i.e. readiness to change and selfperception of efficacy, influence risk?

One hundred. Surveillance programmes have been used in some at-risk industries with different means, at different intervals, and with different approaches [12, 44]. With these experiences, how can an ideal surveillance programme be defined? Besides using questionnaires, should surveillance programmes include serial measures of AHR?

\section{CONCLUSIONS}

Many questions regarding work-related asthma remain unanswered despite recent advances. It is hoped that clarifying these questions will enhance further advances in research and knowledge within the field in the coming years.

\section{ACKNOWLEDGEMENTS}

The invited Workshop members who provided input and review are listed per section as follows. A formal overview was given by presenters $(\mathrm{P})$ and discussion of topics was led by discussion leaders (DL).

Introductory overview: A. Newman-Taylor (P) and M. ChanYeung (P). Definitions: J-L. Malo (P); O. Vandenplas (DL); I.L. Bernstein (DL); G. Wagner (DL); and S. Brooks. How often? P. Blanc (P); J.M. Anto (DL); D. Gautrin; U. Latza; C. Redlich (DL); and H. Allmers. Who gets OA? Personal characteristics: D. Bernstein (P); D. Gautrin (DL); C. Mapp (presented in absentia by P. Maestrelli (DL)); A. Newman-Taylor (DL); A. Siracusa; and D. Banks. Irritants and asthma variants: S.M. Tarlo (P); S. von Essen (DL); R. Balkissoon (DL); 
P. Henneberger (DL); P. Blanc; S. Brooks; D. Gautrin; K. Toren; H. Kipen; and M. Becklake. Pathogenesis: A. Wisnewski (P); G. Moscato (DL); W. Brown (DL); B. Nemery; A. Jolly; P. Maestrelli; and C. Lemière. QoL and disability assessment: K. Rosenman (P); W. Beckett (DL); D. Muir; J. Ameille (DL); A. Cartier (DL); S. Quirce; D.L. Holness; and K.L. Lavoie. Environmental influences: D. Heederik (P); M. Swanson (DL); A. Jolly (DL); J. Bernstein (DL); F. Silverman; H. Nordman; Y. Cloutier; J. Lesage; and K. Pacheco. Persistence and remodelling: A. Siracusa (P); M. Chan-Yeung (DL); D. Banks (DL); and L. Petsonk (DL). Diagnosis: C. Lemiere (P); D. Muir (DL); P.S. Burge (DL); S. Quirce (DL); O. Vandenplas; D. Banks; D. Bernstein; L. Perfetti; J. Sastre; T. Aasen; F.E. Hargreave; J. Cote; and K. Maghni. Prevention: P. Cullinan (presented in absentia by A. Brant; P); B. Nemery (DL); G.M. Liss (DL); S.M. Tarlo; M. Labrecque; and D. Hendrick. Any invited participant could contribute to any component of the Symposium in addition to the topic allocated.

The authors would like to thank the University Health Network and Gage Occupational and Environmental Health Unit, Toronto (ON, Canada) for administrative/facility support.

\section{REFERENCES}

1 Chan-Yeung M, Malo JL, Tarlo SM, et al. Proceedings of the first Jack Pepys Occupational Asthma Symposium. Am J Respir Crit Care Med 2003; 167: 450-471.

2 Mapp CE, Boschetto P, Maestrelli P, Fabbri LM. Occupational asthma. Am J Respir Crit Care Med 2005; 172: 280-305.

3 Gautrin D, Newman-Taylor AJ, Nordman H, Malo JL. Controversies in epidemiology of occupational asthma. Eur Respir J 2003; 22: 551-559.

4 Moscato G, Malo JL, Bernstein D. Diagnosing occupational asthma: how, how much, how far? Eur Respir J 2003; 21: 879-885.

5 Vandenplas O, Malo JL. Definitions and types of workrelated asthma: a nosological approach. Eur Respir J 2003; 21: 706-712

6 Cullinan P, Tarlo S, Nemery B. The prevention of occupational asthma. Eur Respir J 2003; 22: 853-860.

7 Mapp CE. The role of genetic factors in occupational asthma. Eur Respir J 2003; 22: 173-178.

8 Vandenplas O, Toren K, Blanc PD. Health and socioeconomic impact of work-related asthma. Eur Respir J 2003; 22: 689-697.

9 Karjalainen A, Martikainen R, Karjalainen J, Klaukka T, Kurppa K. Excess incidence of asthma among Finnish cleaners employed in different industries. Eur Respir J 2002; 19: 90-95.

10 Reinisch F, Harrison RJ, Cussler S, et al. Physician reports of work-related asthma in California, 1993-1996. Am J Ind Med 2001; 39: 72-83.

11 Kopferschmitt-Kubler MC, Ameille J, Popin E, et al. Occupational asthma in France: a 1-yr report of the observatoire National de Asthmes Professionnels project. Eur Respir J 2002; 19: 84-89.

12 Tarlo SM, Liss GM, Yeung KS. Changes in rates and severity of compensation claims for asthma due to diisocyanates: a possible effect of medical surveillance measures. Occup Environ Med 2002; 59: 58-62.

13 Gannon PF, Burge PS. A preliminary report of a surveillance scheme of occupational asthma in the West Midlands. Br J Ind Med 1991; 48: 579-582.

14 Medina-Ramon M, Zock JP, Kogevinas M, Sunyer J, Anto JM. Asthma symptoms in women employed in domestic cleaning: a community based study. Thorax 2003; 58: 950-954.

15 Tarlo SM, Leung K, Broder I, Silverman F, Holness DL. Asthmatic subjects symptomatically worse at work: prevalence and characterization among a general asthma clinic population. Chest 2000; 118: 1309-1314.

16 Petsonk EL. Work-related asthma and implications for the general public. Environ Health Perspect 2002; 110: Suppl. 4 , 569-572.

17 Sunyer J, Anto JM, Tobias A, Burney P. Generational increase of self-reported first attack of asthma in fifteen industrialized countries. European Community Respiratory Health Study (ECRHS). Eur Respir J 1999; 14: 885-891.

18 Albin M, Rylander L, Mikoczy Z, et al. Incidence of asthma in female Swedish hairdressers. Occup Environ Med 2002; 59: 119-123.

19 Balmes J, Becklake M, Blanc P, et al. American Thoracic Society Statement: Occupational contribution to the burden of airway disease. Am J Respir Crit Care Med 2003; 167: 787-797.

20 Quirce S. Eosinophilic bronchitis in the workplace. Curr Opin Allergy Clin Immunol 2004; 4: 87-91.

21 Ameille J, Pauli G, Calastreng-Crinquand A, et al. Reported incidence of occupational asthma in France, 1996-1999: the ONAP programme. Occup Environ Med 2003; 60: 136-141.

22 Venables KM, Upton JL, Hawkins ER, et al. Smoking, atopy, and laboratory animal allergy. Br J Ind Med 1988; 45: 667-671.

23 Gautrin D, Infante-Rivard C, Ghezzo H, Malo JL. Incidence and host determinants of probable occupational asthma in apprentices exposed to laboratory animals. Am J Respir Crit Care Med 2001; 163: 899-904.

24 Sarlo K. Control of occupational asthma and allergy in the detergent industry. Ann Allergy Asthma Immunol 2003; 90: 32-34.

25 Saary MJ, Kanani A, Alghadeer H, Holness DL, Tarlo SM. Changes in rates of natural rubber latex sensitivity among dental school students and staff members after changes in latex gloves. J Allergy Clin Immunol 2002; 109: 131-135.

26 Von Essen S. The role of farm exposures in occupational asthma and allergy. Curr Opin Allergy Clin Immunol 2001; 1: 151-156.

27 Hayes BB, Afshari A, Millecchia L, Willard PA, Povoski SP, Meade BJ. Evaluation of percutaneous penetration of natural rubber latex proteins. Toxicol Sci 2000; 56: 262-270.

28 Passalacqua G, Ciprandi G, Canonica GW. The nose-lung interaction in allergic rhinitis and asthma: united airways disease. Curr Opin Allergy Clin Immunol 2001; 1: 7-13.

29 Lemiere C. The use of sputum eosinophils in the evaluation of occupational asthma. Curr Opin Allergy Clin Immunol 2004; 4: 81-85.

30 Maghni K, Lemiere C, Ghezzo H, Yuquan W, Malo JL. Airway inflammation after cessation of exposure to agents 
causing occupational asthma. Am I Respir Crit Care Med 2004; 169: 367-372.

31 Malo JL, Boulet LP, Dewitte JD, et al. Quality of life of subjects with occupational asthma. J Allergy Clin Immunol 1993; 91: 1121-1127.

32 Larbanois A, Jamart J, Delwiche JP, Vandenplas O. Socioeconomic outcome of subjects experiencing asthma symptoms at work. Eur Respir J 2002; 19: 1107-1113.

33 Baur X. I are we closer to developing threshold limit values for allergens in the workplace? Ann Allergy Asthma Immunol 2003; 90: 11-18.

34 Vandenplas O, Cartier A, Lesage J, et al. Prepolymers of hexamethylene diisocyanate as a cause of occupational asthma. J Allergy Clin Immunol 1993; 91: 850-861.

35 Howell MD, Tomazic VJ, Leakakos T, Truscott W, Meade BJ. Immunomodulatory effect of endotoxin on the development of latex allergy. J Allergy Clin Immunol 2004; 113: 916-924.

36 Lemiere C. Non-invasive assessment of airway inflammation in occupational lung diseases. Curr Opin Allergy Clin Immunol 2002; 2: 109-114.

37 Anees W, Huggins V, Pavord ID, Robertson AS, Burge PS. Occupational asthma due to low molecular weight agents: eosinophilic and non-eosinophilic variants. Thorax 2002; 57: 231-236.

38 Obata H, Dittrick M, Chan H, Chan-Yeung M. Sputum eosinophils and exhaled nitric oxide during late asthmatic reaction in patients with western red cedar asthma. Eur Respir J 1999; 13: 489-495.

39 Allmers H, Chen Z, Barbinova L, Marczynski B, Kirschmann V, Baur X. Challenge from methacholine, natural rubber latex, or 4,4-diphenylmethane diisocyanate in workers with suspected sensitization affects exhaled nitric oxide (change in exhaled NO levels after allergen challenges). Int Arch Occup Environ Health 2000; 73: 181-186.

40 Piipari R, Piirila P, Keskinen H, Tuppurainen M, Sovijarvi A, Nordman H. Exhaled nitric oxide in specific challenge tests to assess occupational asthma. Eur Respir J 2002; 20: 1532-1537.

41 Lemiere C, Romeo P, Chaboillez S, Tremblay C, Malo JL. Airway inflammation and functional changes after exposure to different concentrations of isocyanates. J Allergy Clin Immunol 2002; 110: 641-646.

42 Bernstein DI, Cartier A, Cote J, et al. Diisocyanate antigenstimulated monocyte chemoattractant protein- 1 synthesis has greater test efficiency than specific antibodies for identification of diisocyanate asthma. Am J Respir Crit Care Med 2002; 166: 445-450.

43 Poonai N, van Diepen S, Bharatha A, Manduch M, Deklaj T, Tarlo SM. Barriers to diagnosis of occupational asthma in Ontario. Can J Public Health 2005; 96: 230-233.

44 Sarlo K, Kirchner DB. Occupational asthma and allergy in the detergent industry: new developments. Curr Opin Allergy Clin Immunol 2002; 2: 97-101. 